Contato do autor: guilherme.silva.adv@hotmail.com

\title{
DECISÃO JURÍDICA E LEGITIMIDADE: CRIANDO LAÇOS ENTRE DEMOCRACIA E JUSTIÇA
}

\author{
LEGAL DECISION AND LEGITIMACY: CREATING LINKS BETWEEN \\ DEMOCRACY AND JUSTICE \\ Guilherme Raimundo da Silva \\ Faculdade de Direito do Sul de Minas - FDSM - Pouso Alegre - MG - Brasil \\ Rafael Lazzarotto Simioni \\ Faculdade de Direito do Sul de Minas - FDSM - Pouso Alegre - MG - Brasil
}

\begin{abstract}
Resumo: A questão da legitimidade do Direito e da decisão jurídica foi se destacando dentro do período chamado de pós-positivismo jurídico. Este trabalho se preocupou em analisar a legitimidade do Direito sob os aspectos das teorias procedimentalistas, que destacam a legitimidade mediante 0 procedimento democrático, e substancialistas, que apostam na possibilidade de fundamentação de decisões corretas com base em convicções substanciais. A exploração das possibilidades de conciliação entre procedimentalismo e substancialismo abre a discussão sobre a legitimidade do Direito e da decisão jurídica sob uma perspectiva mais próxima à realidade do Estado Democrático de Direito. Nesse esforço de se estabelecer os laços entre procedimentalismo e substancialismo, consequentemente criam-se os laços entre democracia e justiça.
\end{abstract}

Abstract: The question of the legitimacy of the law and legal decision has been standing out in the period called the legal postpositivism. This work bothered to analyze the legitimacy of the law under the aspects of proceduralists theories that highlight the legitimacy through democratic procedure, and substantialists, betting on the possibility of foundation of correct decisions based on substantial convictions. The exploration of possibilities for conciliation proceduralism and substantialism raises issues concerning the legitimacy of the law and legal decision from a closer perspective to the reality of the democratic state. In this effort to establish ties between proceduralism substantialism and consequently it creates links between democracy and justice.

Palavras-chave: Conciliação. Decisão Jurídica. Legitimidade. Procedimentalismo. Substancialismo.

Keywords: Conciliation. Legal Decision. Legitimacy. Proceduralism. Substantialism. 


\section{Introdução}

Em tempos de pós-positivismo jurídico, a tensão entre democracia e constitucionalismo também pode ser reconstruída como uma questão de legitimidade e justiça. Mais do que os antigos problemas de conciliação entre segurança jurídica e justiça típicos das tradições jusnaturalistas, essa questão se intensifica na medida em que permite abrir o diálogo teórico sobre a legitimidade do Direito por meio das teorias procedimentalistas e substancialistas.

O procedimentalismo, de um modo geral, acredita inexistir a possibilidade contemporânea da justificação de decisões jurídicas com base em princípios, valores ou conviç̧ões materiais, especialmente diante da fragmentação dos princípios morais e valores éticos na sociedade globalizada. De modo que, inexistindo princípios e valores universalizáveis, só restam os procedimentos racionais, deontologicamente neutros, de construção e de justificação das decisões. Já o substancialismo, em geral, acredita que mesmo nas sociedades contemporâneas, fragmentadas pelo multiculturalismo e enriquecidas com a experiência da diversidade, ainda é possível encontrar fundamentos e convicções substanciais capazes de justificar adequadamente a correção da decisão jurídica.

Dadas essas premissas, este estudo, marcado pelo debate entre as teorias procedimentalistas e substancialistas, firmou-se a partir das principais ideias de alguns autores que marcaram este ponto do assim chamado "póspositivismo jurídico", no âmbito das teorias da decisão, da argumentação e da interpretação jurídica.

No que segue, esta pesquisa objetiva analisar as condições de possibilidade para uma possível conciliação entre as concepções procedimentalistas e substancialistas da prática jurídica, para assim verificar a possibilidade de se estabelecer um equilíbrio entre democracia e justiça no ápice do debate acerca da legitimidade do Direito.

Em um primeiro momento, esta investigação procurará contextualizar o espaço marcado pela transição do positivismo ao conjunto de teorias que, 
atualmente, na falta de uma nomenclatura melhora, convencionou-se denominar de pós-positivismo jurídico. Transição essa marcada pelo surgimento de diversas e plurais correntes hermenêuticas.

Dentro dessas várias propostas de reformulação do entendimento da práxis jurídica, surgem as correntes procedimentalistas e substancialistas, especialmente nos pensamentos de Jurguen Habermas e Ronald Dworkin, as quais são explicitadas de modo sumário, no sentido de discutir as diferentes exigências de legitimidade da decisão jurídica.

O procedimetalismo, em um primeiro momento, ocupa-se com a utilização dos procedimentos discursivos para que se chegue a um resultado racional legítimo. A existência de métodos corretos e dialógicos faz com que a decisão se legitime através do procedimento. Enquanto o substancialismo se esforça pela aplicação do melhor conceito de justiça para o estabelecimento da legitimidade do Direito. Esse embate proporciona também uma discussão entre os direitos da maioria e os da minoria.

Jurgen Habermas aposta na existência de um novo paradigma do Direito, qual seja: o paradigma procedimentalista, ao passo que os paradigmas de Estado Liberal e Social, na visão do autor, já não atenderiam suficientemente as demandas exigidas pelo Estado Democrático de Direito. $O$ procedimentalismo, por meio de um procedimento discursivo-democráticoracional-dialógico, que ofereça aos cidadãos igualdades de condições com vistas a sua autonomia pública e privada, insurge-se na decisão a fim de possibilitar a melhor forma para se obter um resultado legítimo.

Do outro lado, Ronald Dworkin combate aquilo que ele denomina de visão cética do direito, que não acredita mais na possibilidade de fundamentação convincente do direito em princípios de moralidade política e que, em seu lugar, substitui as convicções morais por procedimentos intersubjetivos. A proposta substancialista, para a justificação das decisões por meio dos princípios e da moralidade política, aponta para uma hermenêutica política comprometida com o ideal de justiça no direito. Para isso sobressai a figura do juiz, chamado por Dworkin de 'Hércules', bem com a metáfora do romance em cadeia e as virtudes do direito. 
Por fim, será esplanada a dificuldade de se diferenciar um juízo material de um juízo formal, bem como analisadas as propostas de conciliação entre regras de procedimento e fundamentos de moralidade política no âmbito da jurisdição constitucional, de modo a se avaliar as condições de possibilidade para um equilíbrio entre legitimidade e justiça.

\section{O assim chamado "pós-positivismo jurídico" e a recuperação do mundo prático na decisão jurídica}

O positivismo desde Locke, Rosseau e Kant, não apenas na filosofia, mas também na realidade constitucional ocidental firmou-se como o verdadeiro conceito de direito (HABERMAS 2007, p.294). Sempre se esperou e lutou para a construção de tanto um direito positivo e coercitivo quanto um direito autônomo, assegurador da liberdade.

O pensamento positivista de Augusto Comte nos insere numa espécie de positivismo filosófico (FONSECA 2012, p.41). O Autor conhecido como pai da corrente positivista, que no pensamento clássico mostra que os direitos só poderão ser entendidos como um engodo das discussões metafísicas. Para Comte não existem direitos. O que existem são deveres e esses é que possuem uma faticidade positiva capaz de explicar as causas dos comportamentos sociais (SIMIONI 2014, p.147).

O positivismo clássico trouxe o modo de se legitimar as matérias das ciências naturais aplicadas ao direito. Diante disso temos a presença dos valores morais, éticos, religiosos e sociais no campo jurídico.

Com o objetivo de superar o pensamento positivista clássico, o neopositivismo kelseniano teve por princípio metodológico na interpretação jurídica, a asseguração da pureza do direito. Kelsen segue a linha do positivismo lógico do Circulo de Viena, com a combinação de aportes teóricos da matriz neokantiana do conhecimento. Kelsen contestava o positivismo clássico e para isso fundava seu argumento no ideal de banir toda e qualquer pressuposição metafísica do conhecimento jurídico (SIMIONI 2014, p.146). 
Para o autor o direito justo não deve se contaminar, e por contaminação, temos toda matéria que adentrando a hierarquia jurídica traga ao topo um elemento que não seja puramente relacionado ao direito. Não há como negar que o neopositivismo trouxe contribuições como a configuração de um direito autônomo capaz de por si só regular as questões que envolvem os sujeitos e também a configuração de um direito hierárquico com a ideia de superioridade constitucional e a (in)validade das normas abaixo da constituição a partir das ferramentas legítimas para tanto.

A sociedade correta era a que estava organizada de acordo com um programa jurídico racional e puro. Todavia, a doutrina da sociedade natural, dos filósofos morais, já manifestara dúvidas em relação à concepção do direito racional, como a resistência à reconstrução do direito formal, dentro das estruturas e contextos naturais, costumes e instituições práticas (HABERMAS 2003, p.66).

Os argumentos positivistas ultrapassam as particularidades históricas e os dados sócio-culturais, opondo-se ao racionalismo. Este racionalismo é o que se preocupa com a introdução não absolutizada das informalidades das relações sociais, costumes, tradições naturais e interesses consensuais para a transformação destas instituições em um sistema de regras legítimo.

Os motivos pós-positivistas foram claros:a preocupação com o resgate dos valores no âmbito da norma. Toda regra é recheada por um valor, haja vista que por traz do sentido deontológico da norma há um sentido originário ontológico.

Habermas (2007, p.296), por exemplo, afirma que o direito positivo temporalizado - no sentido de uma hierarquia de leis - deveria permanecer interligado ao direito moral eternamente válido e receber dele as suas orientações permanentes. Contudo a relação entre ambos se dá mais no âmbito da complementariedade do que da subordinação.

Robert Alexy (2001, p.46) pergunta se é possível realmente um discurso racional ser justificado por conviç̧ões morais. Essa pergunta reflete a preocupação de Alexy em seu procedimentalismo argumentativo justificado pelos princípios e valores, a fim de se estabelecer a legitimidade da decisão, posteriormente exposto. 
Por outro lado Habermas apresenta uma maneira bem sofisticada de se apreciar e aplicar o direito, consubstanciada em um discurso extrínseco e dialógico. Na busca pela legitimidade do direito, Habermas revisita os modernos paradigmas do direito e os modelos democráticos para apresentar um novo paradigma.

Criticando o Positivismo Dworkin analisa que essa corrente conduz o interprete a uma armadilha semântica (SIMIONI 2014, p.326), uma vez que todo direito fica restrito a uma questão de analise linguística, podendo se afastar facilmente dos seus sentidos.

A preocupação com a superação do positivismo puro e com a restrição do Direito à uma análise puramente textual, ocasionou o surgimento de correntes pós-positivistas capazes de recuperar os valores no âmbito da norma jurídica. Essas teorias que aqui serão estudadas são chamadas procedimentalistas e substancialistas. Em um primeiro momento, elas se contraporão, para posteriormente propor uma conciliação.

\section{Procedimentalismo versus substancialismo}

De fato a busca pela legitimidade jurídica marca os autores pósmodernos. Reanalisando os princípios básicos do Estado Democrático de Direito à luz de uma compreensão procedimentalistado direito, Habermas aposta na legitimidade discursivo-procedimental.

O procedimentalismo discursivo é apontado por Habermas como um autêntico paradigma do Direito. Pelo procedimento formal podemos encontrar a garantia da liberdade do convencimento recíproco entre os participantes, entre as normas e seus destinatários.

O Direito positivo tem que legitimar-se, e esse fim seria constituído no sistema jurídico, através do processo legislativo, pois, o lugar da integração social é na legislação. Nesse local supõe-se que os participantes saiam da condição de sujeitos privados do direito e assumam a condição de cidadãos (HABERMAS 2003, p.52-53). Esses cidadãos associados encontrarão o acordo 
sobre os princípios normativos da regulamentação, que poderão ser encontrados nas tradições, nos costumes e no mundo prático. Eis que neste ponto Direito e Democracia se validam conjuntamente através do procedimento discursivo.

A participação política dos cidadãos nos remete a institucionalização jurídica por meio da formação pública de opinião e vontade. Essa formação deve realizar-se em formas de comunicação, nas quais é importante o princípio do discurso, em dois aspectos: O princípio do discurso tem um sentido cognitivo de se filtrar os argumentos para se obter um resultado racional, e um sentido prático de se produzir relações de entendimento, as quais são isentas de violência desencadeando a força produtiva da liberdade comunicativa (HABERMAS 2003, p.191).

O procedimento democrático deve sempre fundamentar a legitimidade do direito. Compreende-se que a visão procedimentalista de Habermas exclui a possibilidade de existência de um Estado de Direito, ou o império das regras positivas, desligado da democracia, esta pautada na autonomia interna garantida ao cidadão. O ideal seria o Estado Democrático de Direito no qual se verifica a coesão interna entre Direito e Democracia.

O Direito moderno positivo é histórico, contingente, modificável e coercitivo por um lado e garantidor de liberdade de outro. Se as normas positivas podem ser modificadas, então é necessário legitimação para tal circunstância. O Direito necessariamente deve garantir autonomia de todos os seus sujeitos. Segundo Habermas (2007, p.287) o processo legislativo democrático deve ser suficiente para atender essa exigência. $E$ nesse sentido cria-se uma relação conceitual ou interna entre Direito e Democracia e não apenas uma relação historicamente casual.

Não há aqui especificação e indicação dos conteúdos ou temas, mas de como os participantes podem chegar a um consenso livre e universalmente válido a respeito dos conteúdos normativos. A razão prática - o que devo fazer - é substituída pela razão comunicativa - como devo proceder para saber o que devo fazer - que permite daí, à comunidade linguística levantar pretensões de validade suscitadas argumentativamente. No Discurso Jurídico a legitimidade não pode ser imposta por uma instituição, mas deve ser 
estabelecida perante a validade procedimental do discurso. Não cumpre, pois ao Direito o papel de colonizador do "mundo vivido", ou burocratizador das relações sociais, devendo apenas instituir procedimentos de regulação dos conflitos em conformidade com as estruturas da ação ordenadas ao entendimento (SIMIONI 2001, p.218).

A busca pela legitimidade a partir de Habermas leva a considerar 0 discurso jurídico, como um caso especial do discurso moral, atado a sistemas de normas e procedimentos, cuja pretensão de correção reside na sinceridade dos falantes e na fundamentação de seu valor prático no contexto de uma teoria do Estado e do Direito.

Ainda na esteira do procedimentalismo, contudo em um caminho diferente temos a Teoria da Argumentação Jurídica de Robert Alexy. Esta busca a justificação das decisões através de procedimentos de discussão racional, cujos critérios são aplicados aos princípios e valores, uma vez que o alcance das convicções morais, por si só, dificilmente pode chegar a um consenso em razão da extensão e complexidade das sociedades modernas.

Os discursos jurídicos se relacionam com a justificação (ALEXY 2001, p.218) e para tanto é necessária a adesão a procedimentos racionais, capazes de resultar em uma decisão legítima, visitando os princípios morais, contudo impossibilitando a generalização objetiva destes princípios. O correto se apresenta na medida em que a argumentação realiza um procedimento de discussão racional a respeito do conteúdo substancial dos princípios.

O procedimentalismo propõe a renuncia às pretensões de justificação baseada em princípios substanciais e substituí-la por uma justificação baseada no cumprimento de procedimentos de discussão racional (SIMIONI 2014, p.146).

Somente a validade do procedimento justificará a legitimidade do resultado. Mesmo que não seja possível a observação rígida das regras do procedimento, é necessário que haja uma aproximação eficaz no estabelecimento de tais regras para que haja validade.

Alexy neste ponto estabelece uma aproximação com o pensamento procedimentalista de Habermas, elencando critérios para que a argumentação se forme racionalmente. 
$O$ argumentador deve buscar 0 acordo entre os participantes do discurso, para o estabelecimento de um discurso sincero e sério. Somente se chegará ao consenso quando se convencer a todos a respeito da norma e isto só é possível quando todos os participantes forem ouvidos, abertos a críticas e assim chegarem a uma aceitação recíproca por aquela a norma (ALEXY 2001, p.139).

Contudo Alexy se afastará de Habermas quando não estabelece que o consenso será fundamental para a interpretação e aplicação de uma norma ou decisão jurídica, verificando que a validade não estará na aceitação racional ou no consenso, mas no cumprimento das regras procedimentais do discurso (SIMIONI 2014, p.249-250).

A proposta procedimentalista diante da concepção habermasiana apresenta o procedimento como ideal de validade e legitimação de uma decisão, uma vez que o procedimentalismo é universal, não varia, pois o que é válido agora o será em qualquer tempo, enquanto o que é substancial não será universal, uma vez que seu conteúdo é relativo, ou seja, o que é válido hoje para a comunidade não o poderá ser em outro tempo.

O substancialismo contrapondo o procedimentalismo apresenta outra maneira de se obter a legitimidade do direito na pós-positividade.

Dentro do substancialismo se torna mais evidente a linha interpretativa das regras e direitos a partir da observância dos princípios e valores morais de uma comunidade, para a garantia e efetivação dos direitos fundamentais neste espaço. Os princípios e valores morais da comunidade estão além dos meros textos legais e o fundamento do Direito vai além da convenção procedimental legislativa. Nesse âmbito ganham relevância as decisões judiciais aplicadas ao caso em concreto, no sentido de legitimação das pretensões das minorias.

Contudo a concepção dworkiniana não orienta a compreensão de que o magistrado tem autorização para decidir conforme suas decisões e convicções pessoais e suas ideologias. Ao contrário ele utiliza a metáfora do Juiz Hércules que deveria ser empregado na solução dos casos novos ou difíceis, ou seja, casos desprovidos de uma pré-compreensão capaz de basear efetivamente a decisão. 
Dworkin estabelece uma alternativa, através do principio da integridade, que se preocupa como os indivíduos podem ter outros direitos, além dos criados de uma decisão ou na prática expressa. Como se pode ter direito ao reconhecimento judicial de uma prerrogativa quando não existem decisões judiciais ou práticas sociais inequívocas que conferem decisão em favor desta perspectiva. A integridade pressupõe equidade e justiça (DWORKIN 2002). Desse modo não há criação do Direito pelos magistrados, mas construção dos direitos pelas partes a partir dos princípios, portanto abandona-se a perspectiva unilateral das regras apontada pelo positivismo (DWORKIN 2003).

Se neste caso a legitimidade do Direito está nas pretensões e convicções pessoais de moralidade política de um grupo comunitário, a teoria procedimentalista não teria como se adequar, uma vez que se mostraria insuficiente (SIMIONI 2014, p.315). Por isso a proposta substancialista indaga ainda: Como o procedimentalismo discursivo-democrático pode se estabelecer em países que ainda não obtiveram o cumprimento efetivo das promessas da modernidade, no qual os espaços de opinião pública ainda não fornecem a autonomia ideal aos cidadãos?

Nesse ponto, argumenta-se que o ideal democrático não se efetivaria apenas nos poderes políticos eleitos estabelecidos na Constituição e no procedimento legislativo. Observando-se a tripartição dos poderes bem como o sistema checks and balances, é cediço que todos exercem função essencial e de igual contribuição na teoria do Estado Democrático de Direito, inexistindo hierarquia.Porque então o judiciário, diante de um legislativo e um executivo omissos na maioria das questões, não poderia se estabelecer também como um órgão democrático?

Cappelletti (1999, p.95-96) afirma que mesmo no melhor dos mundos possíveis, a liderança política executiva e legislativa, embora tradicionalmente considerada "diretamente responsável pelo povo", nunca constitui perfeito paradigma de democracia representativa. $\mathrm{O}$ fato que o caráter democrático dos processos legislativo e executivo seja submetido a limitações e condicionamentos reais, frequentemente inevitáveis, salvaguarda a ideia de democracia representativa, e que o judiciário como guardião do procedimento 
não estaria, ao contrario do que tradicionalmente se entendeu inteiramente privado de representatividade.

Nesse sentido a atuação judicial se justifica como um importante mecanismo de representação, até porque a democracia não se esgota na ideia majoritária - no jogo político eleitoral, parlamentar ou governamental -, sendo relevante que suas decisões possam também ir contra a deliberação da maioria. Assim a magistratura politicamente independente tende a desempenhar um papel indispensável para a democracia (CAPPELLETTI 1999, p.95-96).

O procedimentalismo puro ainda não estaria apto a resolver a questão fundamental do Estado Democrático de Direito, ou o equilíbrio entre Constitucionalismo e Democracia, entre a regra contramajoritária e as mudanças políticas pela vontade das maiorias democráticas (SIMIONI 2014, p.321).

Em Dworkin a moral política não é uma moral majoritária, mas uma moral justa e justificável a fim de se respeitar a coerência e a integridade. Para isso tem-se um ponto de partida qual seja o caso prático.

As proposições do juiz Hércules partem da experiência prática de um juiz que precisa decidir os casos concretos e que tem a sua disposição diversas teorias positivistas e pós-positivistas. Trata-se de uma interpretação que experiencia a prática da decisão jurídica e decide politicamente esta interpretação buscando uma justificação coerente e íntegra (SIMIONI 2014, p.331-332). A decisão trará apenas uma resposta correta, pois o que a validará não seria o juiz que a proferiu ou a regularidade do procedimento, mas a qualidade e a justificação principiológica do que estaria sendo discutido.

Entre substancialismo e procedimentalismo reside uma indagação na medida em que as teorias vão sendo analisadas. Esta indagação possui núcleo na aplicação prática no cenário jurídico brasileiro. O magistrado hercúleo de Dworkin seria tão idealizado quanto o procedimento racional discursivo de Habermas neste país cujas propostas modernas não se estabeleceram efetivamente? Qual teoria seria mais relevante nesta perspectiva jurídica? 


\section{Procedimentalismo versus substancialismo: possibilidade de conciliação}

A proposta de se estabelecer um encontro conciliatório entre as teorias procedimentalista e substancialista se aloca no momento em que é insuficiente a hipótese de que o Judiciário apenas atuaria como defensor da Democracia, não podendo em sua função ultrapassar as regras do procedimento pelo procedimento, bem como seria insuficiente pensar que o mesmo órgão ficaria imune da sedução da decisão arbitrária conforme sua conviç̧ão pessoal e desvinculada da vontade de política de uma comunidade.Desse modo tem-se impossibilidade de uma decisão se firmar apenas na forma ou apenas no conteúdo ou ainda apenas no procedimento democrático ou na decisão justa e justificável naquele caso especial (OLIVEIRA 2010, p.137-138).

A situação ideal de comunicação discursiva é tão contrafática quanto o Juiz Hércules, tanto que os próprios autores - Habermas e Dworkin reconhecem seus caráteres idealizados. De fato, a idealização não conhece fronteiras na transcendência da facticidade, porém na realidade poderemos empregar os argumentos apenas em escala aproximativa. Portanto não há como se empregar puramente alguma das teorias, do mesmo modo que emprega-las isoladamente. Sempre haverá uma aproximação de aplicação entre ambas no caso prático e essa aproximação ensejará a possibilidade de conciliação.

Esta aproximação entre as teorias é exemplificada por Oliveira (2010, p.139) quando mostra quão é difícil se conceituar a Democracia. Para se saber se aquele procedimento é democrático ou não exige-se a declaração de um juízo substancial. As várias concepções de Democracia bem como dos direitos e obrigações dela decorrentes exigem a pré-compreensão do que seriam os princípios democráticos, para assim se obter a resposta se o procedimento utilizado em determinado caso foi ou não democrático. Essa resposta é primordialmente obtida por uma decisão de base material e não formal.

Assim coloca-se diante da proposição de que toda teoria procedimentalista possui gênese em uma teoria material ou substancial. Desse 
modo compreende-se o porquê do judiciário ou dos Tribunais Constitucionais exercerem não somente função de guardião da Democracia e da Constituição, e julgadores dos processos para análise de legitimidade de seu procedimento, mas também julgadores da legitimidade dos conteúdos.

Teixeira (2002, p.157) critica um procedimento acima do resultado, esquecendo-se que o rito formal comunicativo é tão somente um instrumento para se chegar a uma pretensão de solução racional. Ora o episódio principal da decisão não é a troca discursiva em si: o processo é um movimento em busca de um veredicto; processo é meio, não fim.

A decisão em si mostra-se muito mais importante do que o procedimento ultrapassado para obtê-la. É necessário, porém, uma análise aprofundada do que seria procedimento democrático e decisão conteudística para então se encontrar o caminho mais próximo da legitimidade.

Alguns exemplos: o entendimento que afirma a obrigatoriedade de realizar a transfusão de sangue frente a negativa das testemunhas de jeová, em conflito portanto, com o desejo do próprio paciente, infringe o procedimento democrático de deliberação? (OLIVEIRA 2010, p.143) O entendimento de que é possível a realização de aborto de feto anencefálico colocaria em pauta uma questão processual ou material? O que dizer das normas que negam direito ao voto de estrangeiros residentes no país e a restrição de elegibilidade aos analfabetos? E quanto aos naturalizados que não podem ocupar funções estatais? Todos esses juízos importam em exame de valor (OLIVEIRA 2010, p.145-147). Para se chegar a uma decisão legítima e que respeite o procedimento democrático há sempre que se passar por um juízo de justiça fundamentado nos princípios democráticos.

Vence-se o entendimento de que somente as decisões legislativas, em primeiro lugar e executivas em segundo é que são legítimas, por serem esses os órgãos representantes do povo que possui poder do agir comunicativo. Neste contexto emprega-se a pergunta: até que ponto a minoria deve estar submissa às decisões da maioria? Somente o legislativo e o executivo representariam legitimamente a vontade do povo? 
Com efeito, é muito pouco, pouquíssimo mesmo, exigir-se aos atos do Poder Público tão só a observância dos procedimentos constitucionais ou legais que condicionam a sua regular edição (CASTRO 1989, p.161). Trata-se de um pensamento um tanto quanto reducionista afirmar que a legitimidade de uma decisão só pode ser verificada em um procedimento. Como afirma Rawls que a justiça procedimental é imperfeita porque não há nenhum processo político factível que garanta que as leis estabelecidas por seus parâmetros serão justas. Nas atividades políticas não é possível atingir uma justiça procedimental perfeita (OLIVEIRA 2010, p.149).

Há, portanto uma dificuldade de se separar o processo da substância. No campo procedimental exige que o legislador se paute em juízos substantivos para se valer da razoabilidade e adequabilidade das questões. $O$ mesmo se diz para o administrador e para o juiz. Quanto mais democrático um processo maiores chances se terá de uma boa decisão (OLIVEIRA 2010, p.159).

Há uma confusão entre a Democracia e Justiça. A presunção de que a razão está com a maior parte das pessoas, uma vez obtida através de um procedimento democrático é relativa, e pode ser refutada ou aperfeiçoada posteriormente. Habermas também reconhece que não é seguro que a decisão oriunda de um processo de debates seja absolutizada e acertadamente justa. De fato, a unanimidade não possui a certeza da verdade ou da justiça. Ao contrário também de Dworkin, levar os direitos a sério é compreender que as pessoas possuem direitos contra o Estado, contra a legislação, mas igualmente contra a própria comunidade (OLIVEIRA 2010, p.151).

Também não se acalenta qualquer visão encantada do Poder Judiciário. O juiz não é necessariamente mais capacitado ou preparado que o legislador ou o administrador, ou que o julgador estaria em uma posição melhor do que os agentes eleitos (OLIVEIRA 2010, p.157). O que se pretende é compreender que isoladamente as teorias não causariam o mesmo impacto que juntas podem efetuar dentro do sistema jurídico-democrático de Direito. A Teoria mista ou conciliação entre procedimentalismo e substancialismo pode mais se identificar com um Estado Democrático de Direito como o brasileiro. 


\section{Considerações finais}

Com os desenvolvimentos teóricos dos esforços de justificação das decisões jurídicas, atualmente reunidos sob o nome de "pós-positivismo jurídico", a interpretação e aplicação estritamente textual do Direito foi sendo aos poucos refutada. Na contemporaneidade desenvolvem-se, assim, novas formas de se olhar o Direito, a partir não só da sua referência normativa a textos ou precedentes, mas também a fundamentos e a finalidades do mundo prático: daí a discussão da sua legitimidade.

A legitimidade do Direito, na visão procedimentalista, verifica-se no procedimento democrático, racional e consensual, destacando a importância da Democracia no Estado de Direito. Por outro lado, na visão substancialista, a legitimidade é descoberta quando o conteúdo da decisão se torna justo perante os cidadãos a ele direcionados, consolidando um destaque maior ao sentimento de moralidade política ou justiça de determinada comunidade.

A jurisdição constitucional no Estado Democrático de Direito brasileiro se depara cada vez mais com o crescimento dos conflitos jurídicos. Enfrenta-los exclusivamente sob o enfoque procedimentalista ou substancialista é uma alternativa muito melhor do que a manter-se na visão modernista do positivismo jurídico clássico. Contudo, o entendimento da prática jurídica que mais se adéqua ao cenário jurídico contemporâneo só pode partir de uma ótica mista, capaz de desencadear argumentos jurídicos transpositivos que necessitam, ao mesmo tempo, fundamentar e validar o procedimento e a decisão.

Ao passo que as decisões oriundas dos órgãos de debate político por meio do processo legislativo democrático se legitimam pelo próprio procedimento, o que não deixa de emitir a princípio um juízo substancial, as decisões oriundas do órgão judiciário também emitem a vontade comunitária ao passo que se legitimam pela busca da verdade e da justiça que muitas vezes não é atingida unicamente pelo processo discursivo democrático. 
As propostas procedimentalistas e substancialistas, diante deste dificultoso desafio de se afastar o processo da substância ou vice versa, fazem com que a decisão jurídica no Estado Democrático de Direito não se legitime apenas pela observação da regra majoritária, mas também pela justa apreciação dos anseios da minoria.

Diante disso, aposta-se na melhor forma de se equilibrar Democracia e Justiça para que as decisões não excluam a forma dialógica e os mecanismos que deram origem a sua construção, mas também não abandone os conteúdos substanciais e a moralidade comum de um grupo, objetivando sempre a conciliação entre forma e matéria, procedimento e substância, democracia e justiça.

\section{Referências}

ALEXY, Robert. Teoria da Argumentação Jurídica. Trad.Zilda Hutchinson Schild Silva.São Paulo: Landy, 2001.

CAPPELLETTI, Mauro. Juízes Legisladores? Tradução de Carlos Alberto Alvaro de Oliveira. Porto Alegre: Sérgio Antonio Fabris Editor, 1999.

CASTRO, Carlos Roberto de Siqueira. O devido processo legal e a razoabilidade das leis na nova Constituição do Brasil. 2 ed. Rio de Janeiro: Forense, 1989.

DWORKIN, Ronald. Levando os direitos a sério. São Paulo: Martins Fontes, 2002. . O Império do direito. São Paulo: Martins Fontes, 2003.

FONSECA, Marcelo Ricardo. Introdução teórica à história do Direito. 1aㅡ ed. Curitiba: Juruá, 2012.

HABERMAS, Júrgen. Direito e Democracia entre facticidade e validade. Vol. I. 2 ed. Tradução: Flávio BenoSiebeneichler. Rio de Janeiro: Tempo Brasileiro, 2003.

. Direito e Democracia entre facticidade e validade. Vol. II.

2 ed. Tradução: Flávio BenoSiebeneichler. Rio de Janeiro: Tempo

Brasileiro,2003. 
Paulo: Loyola. 2007.

. A inclusão do outro: Estudos de Teoria Política. São

OLIVEIRA, Fábio Correa Souza de. Morte e vida da Constituição dirigente. Rio de Janeiro: Lumen Juris, 2010.

TEIXEIRA, Antonio Braz. Consenso, Verdade e direito. In: Colóquio Internacional: Autoridade e Consenso no Estado de Direito. Coimbra: Almedina, 2002.

SIMIONI, Rafael Lazzarotto. Curso de Hermenêutica jurídica contemporânea: do positivismo clássico ao pós-positivismo jurídico. Curitiba: Juruá, 2014.

SIMINONI, Rafael Lazzarotto. Direito e racionalidade comunicativa. Curitiba: Juruá, 2007. 